\title{
Erectile Dysfunction Medication Use in Veterans Eligible for Medicare Part D
}

\author{
Samantha H. Spencer, PharmD; Katie J. Suda, PharmD, MS; Bridget M. Smith, PhD; \\ Zhiping Huo, MS; Lauren Bailey, MS; and Kevin T. Stroupe, PhD
}

\begin{abstract}
BACKGROUND: Erectile dysfunction (ED) medications are therapeutically effective and associated with satisfaction. Medicare Part D included ED medications on the formulary during 2006 and inadvertently in 2007-2008.
\end{abstract}

OBJECTIVE: To characterize phosphodiesterase-5 inhibitor (PDE-5) medication use among veterans who were dually eligible for Veterans Affairs (VA) and Medicare Part $D$ benefits.

METHODS: Veterans aged $>66$ years who received PDE-5 inhibitors between 2005 and 2009 were included. Veterans were categorized by PDE-5 inhibitor claims: VA-only, Part D-only, or dual users of VA and Part D-reimbursed pharmacies. T-tests and chi-square tests were applied as appropriate.

RESULTS: From 2005 to 2009, the majority (85.2\%) of veterans used VA benefits exclusively for their PDE-5 inhibitors; $11.4 \%$ used Medicare Part D exclusively; and $3.4 \%$ were dual users. The Part D-only group was older, more frequently not black, had a VA copay, and had a higher income $(P<0.03)$. The VA group was more likely to have comorbidities, smoke, and have a history of substance abuse $(P<0.001)$. With the inception of Medicare Part $D$ in 2006, the number of patients filling prescriptions for PDE-5 inhibitors (-68\%) and total number of PDE-5 inhibitor 30-day equivalents dispensed $(-86.7 \%)$ from the VA decreased. Part D prescriptions increased through 2006 (full coverage period) and 2007 (accidental partial coverage) and decreased in 2008. While Part $D$ accounted for only $10 \%$ of PDE-5 inhibitor 30 -day equivalents, it equaled $29.2 \%$ of dispensed tablets. In October 2007, VA PDE-5 inhibitor use returned to 2005 levels.

CONCLUSIONS: Implementation of Medicare Part D reduced VA PDE-5 inhibitor acquisition. However, after removal of PDE-5 inhibitors from the Part $D$ formulary, use of VA pharmacies for PDE- 5 inhibitors resumed. Medication policies outside the VA can affect medication use. Veterans with access to non-VA health care may obtain medications from the private sector because of VA restrictions. This may be especially true for nonformulary and lifestyle medications.

J Manag Care Spec Pharm. 2016;22(7):818-24

Copyright $\odot 2016$, Academy of Managed Care Pharmacy. All rights reserved.

\section{What is already known about this subject}

Medications used for the treatment of erectile dysfunction (ED) are effective for most patients and are well tolerated.

While ED medications are not included on the Medicare Part D formulary, veterans have access to these medications on the Veterans Affairs (VA) formulary.

\section{What this study adds}

During the period when PDE-5 inhibitors were allowed on the Medicare Part D formulary, PDE-5 inhibitor prescriptions from VA pharmacies decreased, while PDE-5 inhibitor fills from Medicare-reimbursed pharmacies increased. However, this trend reversed after PDE-5 inhibitors were removed from the Part D formulary.

VA formulary restrictions can increase the likelihood that veterans who have access to non-VA health care obtain medications from the private sector. Since use of non-VA pharmacies may be unknown to VA providers, these veterans may be at a higher risk of adverse events or drug interactions. This is especially a concern for lifestyle drugs, such as those used for ED.

T rectile dysfunction (ED) is defined as "the inability to 1 achieve or maintain an erection sufficient for satisfactory sexual performance." The prevalence of ED increases with advancing age and chronic conditions. ${ }^{1}$ In 1998, sildenafil, the first oral phosphodiesterase-5 inhibitor (PDE-5) was approved, and subsequently in 2003, vardenafil and tadalafil were approved. ${ }^{2}$ In ED treatment guidelines, the oral PDE-5 inhibitors are considered first-line therapy for ED. ${ }^{3}$ Sildenafil was added to the Veterans Affairs (VA) National Formulary in 2001. ${ }^{4}$ In the Veterans Health Administration System (VHA), the use of PDE-5 inhibitors was estimated to be 105.2 patients per 1,000 male veterans during the fiscal years 2004 to $2005 . .^{5}$ In 2006, vardenafil was added to the VA National Formulary. ${ }^{6}$ Veterans who use PDE-5 inhibitors for ED are limited to 4 doses per month through VA pharmacy benefits (VHA Pharmacy Benefits Management Services, "Prescribing and Dispensing Information for Sildenafil [Viagra] and Other PDE Type 5 Inhibitors for the Treatment of Erectile Dysfunction," memo, December 27, 2005).

On January 1, 2006, the Medicare Prescription Drug, Improvement, and Modernization Act (MMA) established coverage for prescription medications through the Medicare Prescription Drug Benefit (Medicare Part D). ${ }^{7}$ Any medication that meets the definition of a Part D drug is required by MMA to be covered by the Part D program. Originally, ED drugs were covered under the Part D benefit; however, Congress eventually amended the MMA to exclude ED drugs from required 
coverage. This new classification began on January 1, 2007, and ED drugs used for the treatment of sexual dysfunction or ED did not meet the definition of a Part D drug. An audit conducted by the Office of the Inspector General from November 2009 to September 2010 revealed that some ED medications were mistakenly covered during 2007 and 2008 because the Medicare Drug Data Processing System did not use a complete list of excluded medications. ${ }^{8}$ Over the 2-year span, the Centers for Medicare \& Medicaid Services mistakenly covered $\$ 3,107,220$ in gross drug costs for ED drugs, with the majority (99.4\%) for PDE-5 inhibitors. ${ }^{8}$ The ED medications to be excluded were updated accordingly and the revised formulary was implemented in 2009. ${ }^{8}$

Although data exist for the use of PDE-5 inhibitors at the population level, limited information exists on the use of PDE-5 inhibitors by veterans who are dually using health care by the VA and the private sector. In addition, no information is available on the effect of health policy changes on the use of lifestyle drugs, such as PDE-5 inhibitors. Thus, the objective of this study was to characterize the use of prescription PDE-5 inhibitors by veterans from 2005 to 2009. Particularly, the effect of Part D pharmacy benefits on PDE-5 inhibitor prescriptions was evaluated to determine if Part $\mathrm{D}$ coverage diverted the number of PDE-5 inhibitor prescriptions filled at VA pharmacies or if veterans received PDE-5 inhibitors from both VA and Medicare sources.

\section{Methods}

This was a retrospective cohort study, and detailed methods are described elsewhere. ${ }^{9}$ In brief, starting with a random $10 \%$ sample of male veterans, those who used VA health care, who were presumed alive through December 2007, were aged 66 years or older, and received at least 1 prescription for a PDE-5 inhibitor between January 1, 2005, and December 31, 2009, were included in this retrospective cohort study. The PDE-5 inhibitors that were included in the analysis were sildenafil, tadalafil, and vardenafil. Female veterans and transgender veterans (International Classification of Diseases, Ninth Revision, Clinical Modification [ICD-9-CM] code 302.85) were excluded. Secondary to chronic use of PDE-5 inhibitors for pulmonary hypertension (sildenafil $5 \mathrm{mg}$ or $20 \mathrm{mg}$ orally 3 times daily), veterans with a pulmonary hypertension diagnosis (ICD-9-CM code 416.0) were also excluded. Veterans were categorized into 3 groups based on where claims were submitted for a PDE-5 inhibitor: VA only, Medicare Part D only, and dual users of VA and Medicare Part D. Demographic data were evaluated during the 2006 calendar year.

Demographic information for the study population was obtained from the VA Medical SAS Inpatient and Outpatient Datasets and the VA Enrollment file. ${ }^{10}$ Copayment status was determined through the veterans' priority categories, which were established to manage access to VA care in relation to the VA's resources based on disability and income. Veterans in priority category 1 do not pay any copayments; veterans in categories 2-6 pay copayments for nonservice-connected medications; and veterans in priority categories 7-8 have copayments for all VA medications. Socioeconomic status of veterans' geographic areas by ZIP code (i.e., median household income in the ZIP code) was obtained from census data. Rural/ urban status was based on rural urban community area codes also derived from ZIP codes.

Prescription claims for PDE-5 inhibitors from VA- and Medicare Part D-reimbursed pharmacies were extracted from the VA Managerial Cost Accounting Pharmacy National Data Extract and the Medicare Part D Slim File, respectively, by the generic and brand names. The number of unique patients, total number of tablets, and number of prescriptions were obtained. Thirty-day equivalents were calculated from the prescription quantity and divided by 30 days (e.g, 30 tablets=one 30-day equivalent). Statistical analyses were performed using SAS version 9.3 (SAS Institute, Cary, NC). Descriptive statistics were used for the baseline characteristics. Differences between groups were compared using either a t-test or chi-square test as appropriate. A $P$ value of $<0.05$ was considered statistically significant. The study was approved by the Edward Hines Jr. VA Hospital Institutional Review Board.

\section{Results}

In this sample, 24,745 unique veterans who were aged 66 years and older filled a prescription for a PDE-5 inhibitor from 2005 to 2009. The majority of these veterans used only VA pharmacies $(n=21,083,85.2 \%)$ for their PDE-5 inhibitors over the study period. Only $11.4 \%(n=2,833)$ used Medicare Part D-reimbursed pharmacies exclusively, and 3.4\% ( $\mathrm{n}=829)$ were dual users of VA and Medicare Part D pharmacies. The overall cohort had a mean age of $73.9( \pm 4.8)$ years and was identified primarily as non-Hispanic (95.7\%) and nonblack (87.0\%). The Medicare Part D group was older, more frequently nonblack, had a VA copay, and lived in areas with higher household incomes $(P<0.03$ for all). The VA group was more likely to have comorbidities (diabetes, hypertension, mental health diagnosis, and posttraumatic stress disorder diagnosis); smoke; and have a history of substance abuse $(P<0.001$ for all). Additional baseline characteristics between VA-only users, Medicare Part D-only users, and dual users are presented in Table 1.

From 2005 to 2009, the total number of tablets dispensed was 775,996 , with $24.9 \%$ of tablets dispensed in 2005 (Table 2). Vardenafil and sildenafil represented $55.3 \%$ and $43.0 \%$ of all PDE-5 inhibitor prescriptions dispensed, respectively. Sildenafil was the primary agent earlier in the study period, while vardenafil dominated later in the study period, which was consistent with VA formulary decisions. In 2006, after vardenafil 
TABLE 1 Patient Characteristics, Grouped by Use of Pharmacy Benefits

\begin{tabular}{|c|c|c|c|c|c|c|c|c|}
\hline \multirow{2}{*}{$\begin{array}{l}\text { Characteristic } \\
\text { Mean age } \pm S D,{ }^{a, b} \text { range (in years) }\end{array}$} & \multicolumn{2}{|c|}{$\begin{array}{c}\text { Overall } \\
\mathrm{N}=24,745\end{array}$} & \multicolumn{2}{|c|}{$\begin{array}{l}\text { VA Only } \\
\mathrm{N}=21,083\end{array}$} & \multicolumn{2}{|c|}{$\begin{array}{l}\text { Med-D Only } \\
\mathrm{N}=2,833\end{array}$} & \multicolumn{2}{|c|}{$\begin{array}{l}\text { VA+Med-D } \\
\mathrm{N}=829\end{array}$} \\
\hline & $73.9 \pm 4.8$ & $(67-96)$ & $73.8 \pm 4.7$ & $(67-94)$ & $74.5 \pm 4.9$ & $(67-96)$ & $73.7 \pm 4.7$ & $(67-89)$ \\
\hline \multicolumn{9}{|l|}{ Ethnicity, n (\%)a } \\
\hline Hispanic & 1,055 & (4.3) & 935 & $(4.4)$ & 71 & $(2.5)$ & 49 & $(5.9)$ \\
\hline Non-Hispanic & 23,690 & $(95.7)$ & 20,148 & $(95.6)$ & 2,762 & $(97.5)$ & 780 & $(94.1)$ \\
\hline \multicolumn{9}{|l|}{ Race, $n(\%)^{a}$} \\
\hline Nonblack & 21,533 & $(87.0)$ & 18,230 & $(86.5)$ & 2,574 & $(90.9)$ & 729 & $(87.9)$ \\
\hline Black & 3,143 & $(12.7)$ & 2,793 & $(13.3)$ & 251 & $(8.9)$ & 99 & (11.9) \\
\hline Missing & 69 & $(0.3)$ & 60 & $(0.3)$ & 8 & $(0.3)$ & 1 & $(0.1)$ \\
\hline \multicolumn{9}{|l|}{ Geographic area, $n(\%)^{a}$} \\
\hline Northeast & 4,035 & $(16.3)$ & 3,398 & $(16.1)$ & 496 & $(17.5)$ & 141 & $(17.0)$ \\
\hline South & 9,627 & $(38.9)$ & 8,057 & $(38.2)$ & 1,216 & $(42.9)$ & 354 & $(42.7)$ \\
\hline Midwest & 5,830 & $(23.6)$ & 5,257 & $(24.9)$ & 438 & $(15.5)$ & 135 & $(16.3)$ \\
\hline West & 4,783 & $(18.1)$ & 3,736 & $(17.7)$ & 585 & $(20.7)$ & 162 & $(19.5)$ \\
\hline Other & 390 & $(1.6)$ & 319 & $(1.5)$ & 48 & (1.7) & 23 & $(2.8)$ \\
\hline Missing & 380 & $(1.5)$ & 316 & $(1.5)$ & 50 & $(1.8)$ & 14 & $(1.7)$ \\
\hline \multicolumn{9}{|l|}{ Residence, $\mathrm{n}(\%)^{\mathrm{a}}$} \\
\hline Urban & 17,348 & $(70.1)$ & 14,532 & $(68.9)$ & 2,177 & $(76.8)$ & 639 & $(77.1)$ \\
\hline Rural & 6,412 & $(25.9)$ & 5,731 & $(27.2)$ & 536 & $(18.9)$ & 145 & $(17.5)$ \\
\hline Missing & 985 & $(4.0)$ & 820 & (3.9) & 120 & $(4.2)$ & 45 & $(5.4)$ \\
\hline \multicolumn{9}{|l|}{ VA copay, $n(\%)^{a, c}$} \\
\hline Priority 1 (no copay) & 2,212 & $(8.9)$ & 2,111 & $(10.0)$ & 63 & $(2.2)$ & 38 & $(4.6)$ \\
\hline Priority 2-6 (copay for some Rx) & 11,541 & $(46.6)$ & 10,160 & $(48.2)$ & 1,000 & $(35.3)$ & 381 & $(46.0)$ \\
\hline Priority 7-8 (copay for all Rx) & 10,954 & $(44.3)$ & 8,799 & $(41.7)$ & 1,746 & $(61.6)$ & 409 & $(49.3)$ \\
\hline Missing & 38 & $(0.2)$ & 13 & $(0.1)$ & 24 & $(0.9)$ & 1 & $(0.1)$ \\
\hline $\begin{array}{l}\text { Median } \pm \text { SD household income (\$) } \\
\text { in ZIP code and (range of values)a,d }\end{array}$ & $\begin{array}{r}42,298 \pm \\
(0-196 \\
\end{array}$ & $\begin{array}{ll}15,927 \\
298)\end{array}$ & $\begin{array}{r}41,893 \pm \\
(0-153\end{array}$ & $\begin{array}{ll}15,555 \\
918)\end{array}$ & $\begin{array}{r}45,074= \\
(0-196 \\
\end{array}$ & $\begin{array}{l}17,975 \\
298)\end{array}$ & $\begin{array}{l}43,137 \\
(8495-7\end{array}$ & $\begin{array}{l}16,877 \\
18553) \\
\end{array}$ \\
\hline \multicolumn{9}{|l|}{ Social history, n (\%) } \\
\hline Substance abuse history ${ }^{\mathrm{a}}$ & 2,968 & $(12.0)$ & 2,729 & $(12.9)$ & 163 & $(5.8)$ & 76 & $(9.2)$ \\
\hline Smoking status ${ }^{\mathrm{a}}$ & 2,747 & $(11.1)$ & 2,497 & $(11.8)$ & 192 & $(6.8)$ & 58 & $(7.0)$ \\
\hline Alcohol use & 653 & $(2.6)$ & 590 & $(2.8)$ & 40 & $(1.4)$ & 23 & $(2.8)$ \\
\hline \multicolumn{9}{|l|}{ Medical history, n (\%) } \\
\hline Diabetes $^{\mathrm{a}}$ & 7,034 & $(28.4)$ & 6,181 & $(29.3)$ & 665 & $(23.5)$ & 188 & $(22.7)$ \\
\hline Hypertension $^{\mathrm{a}}$ & 18,218 & $(73.6)$ & 15,990 & $(75.8)$ & 1,681 & $(59.3)$ & 547 & $(66.0)$ \\
\hline Mental health diagnosis ${ }^{\mathrm{a}}$ & 9,940 & $(40.2)$ & 8,961 & $(42.5)$ & 642 & $(22.7)$ & 337 & $(40.7)$ \\
\hline PTSD diagnosis $^{\mathrm{a}}$ & 593 & $(2.4)$ & 569 & $(2.7)$ & 18 & $(0.64)$ & 6 & $(0.72)$ \\
\hline \multicolumn{9}{|c|}{$\begin{array}{l}\text { cVeterans in priority } 1 \text { category have service-connected conditions that are 50\% or more disabling and are exempt from medication copayments. Veterans in priorities } 2 \text { through } \\
6 \text { have service-connected conditions that are less than } 50 \% \text { disabling, have low incomes, or have other recognized statuses, such as former prisoners of war. These veterans } \\
\text { are exempt from copayments for drugs for their service-connected disabilities. Veterans in priorities } 7 \text { and } 8 \text { are subject to copayments for drugs (VHA Directive 2005-052, } \\
\text { Implementation of Medication Copayment Changes, November 15, 2005). } \\
\text { dP=0.03 for VA-only and VA+Med-D groups. } \\
\text { Med-D }=\text { Medicare Part D; PTSD = posttraumatic stress disorder; Rx=prescription; SD=standard deviation; VA=Veterans Affairs. }\end{array}$} \\
\hline
\end{tabular}

was classified as the preferred PDE-5 inhibitor for the VA, the number of sildenafil prescriptions dispensed by the VA decreased significantly (2005: 53,511 prescriptions, 6,428.9 30-day equivalents; 2006: 6,583 prescriptions, 855.1 30-day equivalents). Based on prescription data for vardenafil, the cohort for this study was not switched until 2007 (0 prescriptions in 2006 vs. 11,304 prescriptions in 2007).
After implementation of Medicare Part D (2006-2009), the majority (89\%) of PDE-5 inhibitor 30-day equivalents were dispensed from VA pharmacies. Interestingly, while Medicarereimbursed pharmacies accounted for only $10 \%$ of PDE- 5 inhibitor 30-day equivalents, they accounted for $29.2 \%$ of the overall tablets dispensed during this time period. PDE-5 inhibitor prescriptions dispensed by Medicare-reimbursed pharmacies had a greater quantity dispensed as compared with those dispensed by 
Erectile Dysfunction Medication Use in Veterans Eligible for Medicare Part D

TABLE 2 Demographics of ED Prescriptions, Grouped by Source

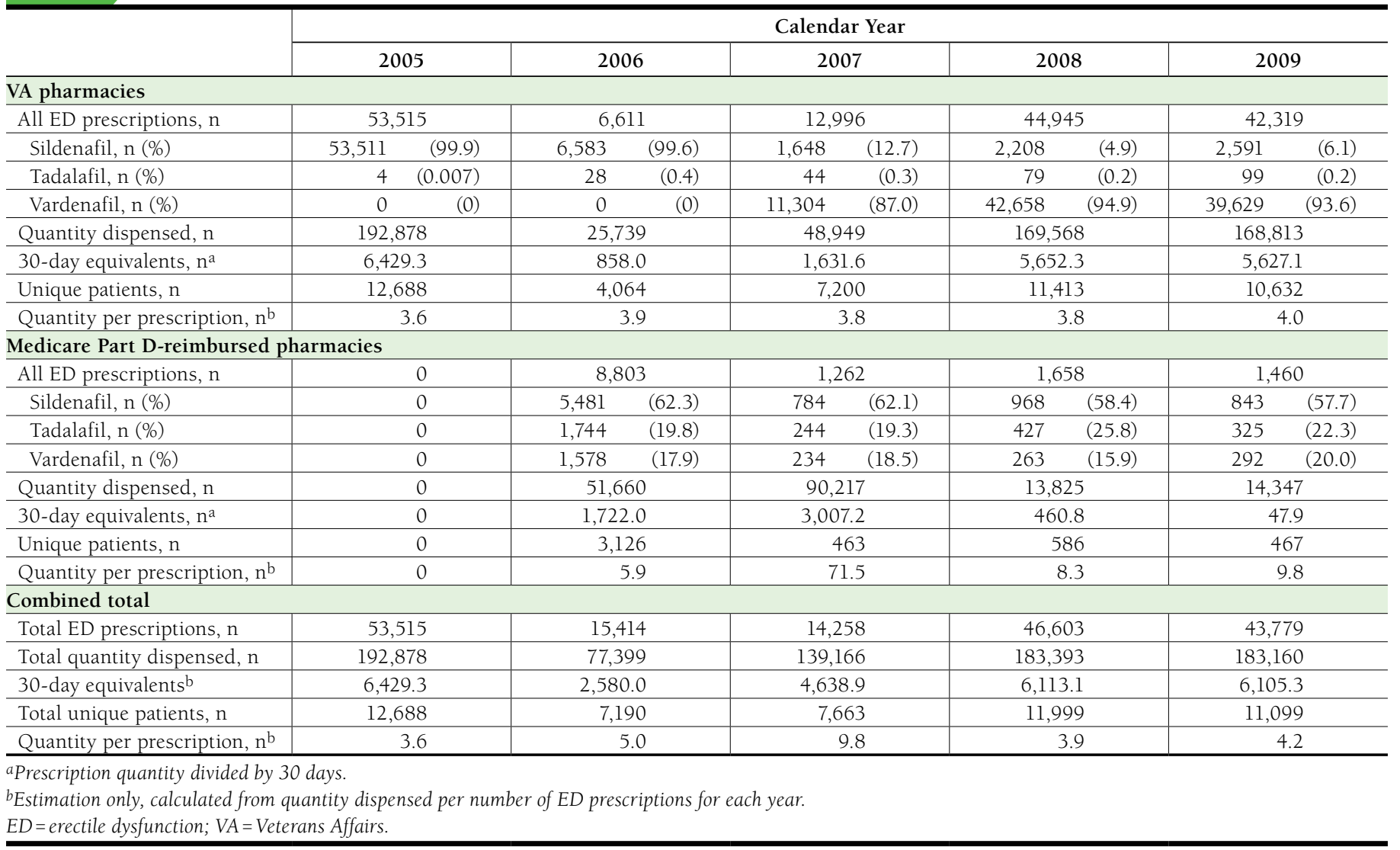

VA pharmacies, with the mean number of prescription dispensed increasing to 71.5 tablets per prescription in 2007 (Table 2).

In 2005, before Medicare Part D implementation, the average number of tablets dispensed monthly was 16,073 . The total number of tablets decreased considerably beginning in January 2006, with a decrease in tablets dispensed through VA benefits without a simultaneous increase of tablets dispensed through Medicare-reimbursed pharmacies (Figure 1). In January and February 2007, during the Medicare coverage period, the total number of tablets exceeded levels before Medicare Part D initiation. In October 2007, the number of tablets dispensed from the VA increased close to baseline but was still a 12.2\% decrease from 2005 levels (average number of tablets dispensed monthly in $2005=16,073$; number of tablets dispensed in October $2007=15,282$; average number of tablets dispensed monthly October 2007-December $2009=14,107$ ). The decrease in the number of tablets dispensed corresponded with a decrease in the number of PDE-5 inhibitor prescriptions, number of 30-day equivalents, and number of unique patients (Table 2).

\section{Discussion}

In this retrospective cohort study, the number of unique patients, prescriptions, 30-day equivalents, and tablets dispensed for PDE-5 inhibitors decreased during the period of dual eligibility for veterans. In addition, there was a small minority of patients who used Medicare Part D benefits for PDE-5 inhibitors. There are several factors that could have influenced the pattern observed in ED medication use during 2005-2009. Vardenafil was added to the VA formulary in 2006 and was phased in as the preferred PDE-5 inhibitor in 2007. ${ }^{6}$ Previously, in 2005, sildenafil represented $95.9 \%$ of all ED prescriptions dispensed at the VA. The formulary switch to vardenafil as the preferred agent greatly decreased sildenafil use. Therefore, the overall drop in number of prescriptions and unique patients for VA pharmacies may be attributed to this formulary switch. Since PDE-5 inhibitors can be considered lifestyle medications, patients may choose to forgo filling these medications if the barrier to access them is increased. Creation of barriers, such as prescription quantity limits, populations excluded from formulary coverage, and higher copayments, were used with the launch of sildenafil by public and private payers in order to limit the financial impact of the 


\section{FIGURE 1 Number of Tablets Dispensed by Source}

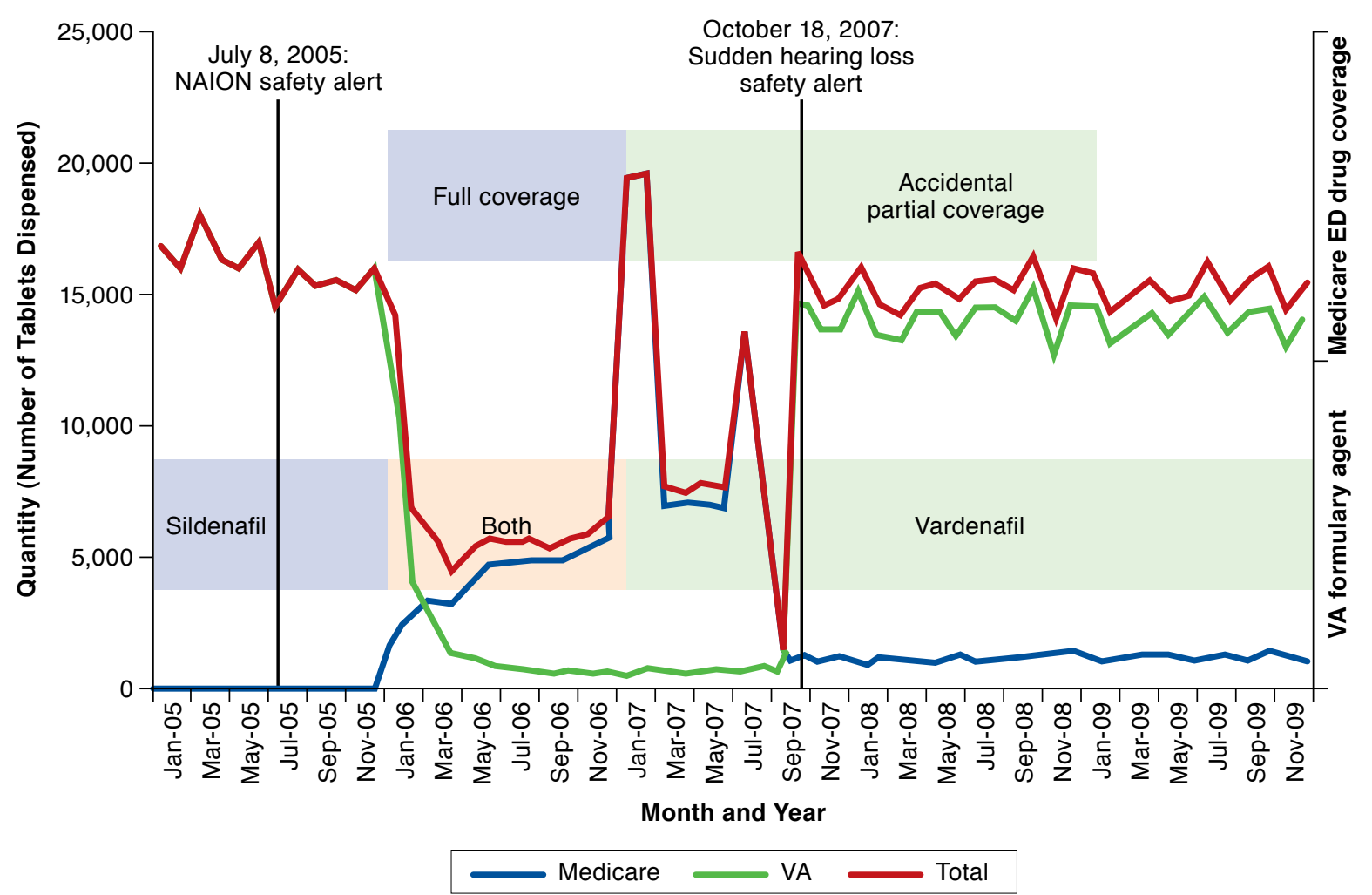

Note: Historical events (Medicare ED drug coverage, VA formulary agent, and FDA safety alerts) are shown.

$E D=$ erectile dysfunction; NAION = nonarteritic anterior ischemic optic neuropathy; VA = Veterans Affairs.

introduction of oral PDE-5 inhibitors. ${ }^{11}$ Additionally, high rates of discontinuation of PDE-5 inhibitors have been reported, even in men with favorable responses to the medication. ${ }^{12-16}$ Surveys assessing patients' reasons for discontinuation have found a wide variety of factors that affect the use of PDE-5 inhibitors: lack of opportunity for intercourse, psychological issues, ineffectiveness, actual or feared adverse effects, high drug cost, and inconvenience in obtaining the medication. ${ }^{12-16}$

Veterans may have chosen to use Medicare benefits because the VA had a quantity limit of 4 tablets per month for the PDE-5 inhibitors. For Medicare, 1 tablet per day was acceptable. In addition, the opportunity to access coverage of Medicare Part D for PDE-5 inhibitors was restricted because of the eventual removal of this drug class from the Part D formulary. Therefore, this limited time frame to access both benefits may have affected dispensed prescriptions for PDE-5 inhibitors. Given that there can be a delay in time before new benefits are used, this could have further limited ability by veterans to use the Medicare Part D benefit. Data from the Health and Retirement Study found that, among Medicare enrollees, $12 \%$ of the population who enrolled at age 65 waited over 2 years before accessing any benefits covered by Part B. ${ }^{17}$ Additionally, the large spike in tablets dispensed by Medicare Part D-reimbursed pharmacies in January 2007 may be secondary to veterans taking advantage of a new benefit cycle and a change in out-of-pocket costs, since Medicare Part D beneficiaries are significantly more likely to reinitiate medications in January. ${ }^{18}$

Safety considerations can also affect the willingness of prescribers or patients to use PDE-5 inhibitors. During this study period, there were 2 safety alerts issued by the U.S. Food and Drug Administration. Alerts regarding risk of nonarteritic anterior ischemic optic neuropathy and risk of sudden hearing loss were released in July 2005 and October 2007, respectively. ${ }^{19,20}$ Based on the number of tablets dispensed, it does not appear that these alerts had a significant impact on PDE-5 inhibitor use.

It was also noted that the number of prescriptions, 30-day equivalents, and tablets dispensed never fully increased back to the 2005 baseline. Decreased use of PDE-5 inhibitors could be secondary to an aging cohort and potential financial recession effects. Throughout the time period, patients may have had more potential disease or drug interactions as the overall cohort aged, complicating medication 
management. Additionally, cohort studies of users of sildenafil in a health maintenance organization in Massachusetts and a large managed care organization in the southeastern and western United States reported that approximately $85 \%$ of members who obtained sildenafil prescriptions were between the ages of 45 and 74 years and ages 40 and 69 years, respectively. ${ }^{21,22}$ Using VA data from 2004 to 2005, veterans were noted to be older, with $74 \%$ of patients receiving PDE-5 inhibitors between the ages of 40 and 69 years, and $23.9 \%$ were aged 70 years or older. ${ }^{5}$ Regarding effects of the recession on medication use, retail prescription sales were compared with state unemployment rates from 2007 to 2010 by Kozman et al. (2012), ${ }^{23}$ who reported an increase in PDE-5 utilization during the recession with a $3 \%$ increase in use per $1 \%$ increase in unemployment.

While the descriptive nature of the study precludes an exact determination of the reasoning for veterans changing how they accessed medications during this time period, this study highlights that veterans may access medications outside of the VA health care system, particularly for lifestyle medications and those with formulary restrictions. This action can complicate medication management if veterans do not report use of these medications to VA providers. A previous survey of veterans found that over one third of veterans receiving medications from non-VA pharmacies indicated never discussing their nonVA medications with their VA physicians. ${ }^{24}$ Therefore, if medication reconciliation is not performed properly, then veterans may be exposed to a higher risk of adverse events and drug interactions when accessing medications from the private sector.

\section{Limitations}

There are several limitations of this study that should be considered. First, diagnosis of pulmonary hypertension was measured by diagnosis codes in the medical record. Therefore, if a patient did not have it as a coded diagnosis, then the inclusion of those patients would inflate the results. This may have affected the data derived from VA sources, especially since VA providers are not reimbursed based on coded diagnoses or treatments. Second, the databases used to capture prescription fills were not be able to capture any prescriptions that were paid for with cash in the private sector. In addition, while an audit revealed that there was a period of accidental coverage under Medicare Part D, it is not known exactly when this was resolved. The audit claimed that by 2009 all national drug codes had been updated, but based on use, this discrepancy appears to have been resolved before 2009. ${ }^{8}$ Finally, secondary to the size of the cohort, a chart review was not performed to detect whether veterans reported outside use of ED medications, which would have helped describe whether VA providers were aware of dual users. Additionally, medical records were only available for patients who were receiving care at the VA (medical records were not available for care received from Medicare-reimbursed providers).
Regardless of these limitations, the results of this study illustrate how changes in pharmacy benefits can affect how patients access and use medications, especially those classified as lifestyle medications. The change in benefits for PDE-5 inhibitors can provide insight into how to manage future changes in prescription medication benefits for a health system. With the changing landscape of the U.S. health care system (e.g., requirements of theAffordable Care Act) that has increased the insured population, policymakers should monitor formulary changes and safety warnings to determine the effect of new policies on medication use. These parameters should specifically include number of patients at risk for events outlined in safety warnings and review of the medication formulary and included National Drug Code numbers. In addition, before a change in the drug formulary and/or a preferred medication, the effect on use and patient adherence should be carefully considered in the outpatient sector.

\section{Conclusions}

From 2005 to 2009, there was an overall reduction in 30-day equivalents for PDE-5 inhibitors and unique patients. During the period of dual coverage, VA PDE-5 inhibitor use decreased, while Medicare Part D PDE-5 inhibitor use increased. However, after ED medications were removed from the Part D formulary, PDE-5 inhibitor medications dispensed from VA pharmacies resumed. Veterans with access to non-VA health care may obtain medications from the private sector because of VA restrictions, especially for nonformulary and lifestyle medications, which complicates medication management.

\section{Authors}

SAMANTHA H. SPENCER, PharmD, College of Pharmacy, University of Illinois at Chicago, Chicago, Illinois; KATIE J. SUDA, PharmD, MS, Center of Innovation for Complex Chronic Healthcare, Hines VA Hospital, Hines, Illinois, and College of Pharmacy, University of Illinois at Chicago, Chicago, Illinois; BRIDGET M. SMITH, PhD, Center of Innovation for Complex Chronic Healthcare, Hines VA Hospital, Hines, Illinois, and Department of Pediatrics, Feinberg School of Medicine, Northwestern University, Chicago, Illinois; ZHIPING HUO, MS, Center of Innovation for Complex Chronic Healthcare, Hines VA Hospital, Hines, Illinois; LAUREN BAILEY, MS, Center of Innovation for Complex Chronic Healthcare, Hines VA Hospital, Hines, Illinois, and Department of Epidemiology and Biostatistics, School of Public Health, University of Illinois at Chicago, Chicago, Illinois; and KEVIN T. STROUPE, PhD, Center of Innovation for Complex Chronic Healthcare, Hines VA Hospital, Hines, Illinois, and Stritch School of Medicine, Loyola University Chicago, Maywood, Illinois

AUTHOR CORRESPONDENCE: Katie J. Suda, PharmD, MS, Center of Innovation for Complex Chronic Healthcare, Hines VA Hospital, 5000 S. 5th Ave., (151H) Bldg. 1B260, Hines, IL 60141-3030. Tel.: 708.202.5204; Fax: 708.202.2316;

E-mail: katiesuda@gmail.com. 


\section{DISCLOSURES}

The authors received funding support for this research project from the Department of Veterans Affairs, Veterans Health Administration, Health Services Research and Development Service as grant IIR 07-165-2. The views expressed in this article are those of the authors and do not necessarily represent the views of the Department of Veterans Affairs or Health Services Research and Development Service.

Study concept and design were contributed by Smith and Stroupe, assisted by the other authors. Huo, Bailey, and Stroupe took the lead in data collection, assisted by the other authors. Data interpretation was performed by Spencer and Suda, along with Smith and Stroupe and assisted by Huo and Bailey. The manuscript was primarily written by Spencer and Suda, with assistance from the other authors, and revised by Spencer, along with the other authors.

\section{REFERENCES}

1. Impotence. NIH Consensus Statement Online. 1992;10(4):1-33. Available at: https://consensus.nih.gov/1992/1992impotence091html.htm. Accessed May 30, 2016.

2. U.S. Food and Drug Administration. Drugs@FDA. Available at: https:// www.accessdata.fda.gov/scripts/cder/drugsatfda/. Accessed June 9, 2016.

3. Montague DK, Jarow JP, Broderick GA, et al. Chapter 1: The management of erectile dysfunction: an AUA update. J Urol. 2005;174(1):230-39.

4. U.S. Department of Veterans Affairs. VA National Formulary. Changes to the VA National Formulary by month--October 1998 to April 2016. Available at: http://www.pbm.va.gov/nationalformulary.asp. Accessed June 9, 2016

5. French DD, Margo CE, Campbell RR. Prevalence of phosphodiesterase-5 inhibitor use in the VHA in 2004 and 2005 is twice that of a commercial health plan in 2001. J Manag Care Pharm. 2006;12(8):692-93. [Letter]. Available at: http://amcp.org/data/jmcp/692-693.pdf.

6. Vardenafil to replace sildenafil on the VA national formulary. PBM MAP Ez-Minutes. Vol 3, Issue 4. October-December 2005. Available at: http:// www.pbm.va.gov/linksotherresources/ezminutes/EZMinutesOctDec05.pdf. Accessed May 30, 2016.

7. Centers for Medicare \& Medicaid Services. Medicare program; policy and technical changes to the Medicare prescription drug benefit. Final rule. Fed Reg. 2008;73(73):20485-20509.

8. Levinson DR. Review of erectile dysfunction drugs in the Medicare Part D program. Office of Inspector General. March 2011. Available at: http://oig. hhs.gov/oas/reports/region7/71003143.pdf. Accessed May 30, 2016.

9. Stroupe KT, Smith BM, Bailey L, et al. Medication utilization of veterans dually eligible for VA and Medicare Part D pharmacy benefits. Am J Health Syst Pharm. In press.

10. U.S. Department of Veterans Affairs. VA Information Resource Center. VIReC research user guide: VHA Assistant Deputy Under Secretary for Health (ADUSH) Enrollment Files. 2nd ed. Hines IL: U.S. Department of Veterans Affairs, Health Services Research \& Development Service, Information Resource Center; September 2013. Available at: http://www. virec.research.va.gov/Resources/RUGs.asp. Accessed June 9, 2016.
11. Klein R, Sturm H. Viagra: a success story for rationing? Health Aff (Millwood). 2002;21(6):177-87.

12. Son H, Park K, Kim SC, Paick JS. Reasons for discontinuation of sildenafil citrate after successful restoration of erectile function. Asian J Androl. 2004;6(2):117-20.

13. Klotz T, Mathers M, Klotz R, Sommer F. Why do patients with erectile dysfunction abandon effective therapy with sildenafil (Viagra)? Int J Impot Res. 2005;17(1)2-4.

14. Jiann B, Yu CC, Su CC, Tsai JY. Compliance of sildenafil treatment for erectile dysfunction and factors affecting it. Int J Impot Res. 2006;18(2):146-49.

15. Carvalheira A, Pereira N, Maroco J, Forjaz V. Dropout in the treatment of erectile dysfunction with PDE5 inhibitors: a study on predictors and a qualitative analysis of reasons for discontinuation. J Sex Med. 2012;9(9):2361-69.

16. Carvalheira A, Forjaz V, Pereira NM. Adherence to phosphodiesterase type 5 inhibitors in the treatment of erectile dysfunction in long-term users: how do men use the inhibitors? Sex Med. 2014;2(2):96-102.

17. Sloan FA, Acquah KF, Lee PP, Sangvai DG. Despite 'welcome to Medicare' benefit, one in eight enrollees delay first use of Part B services for at least two years. Health Aff (Millwood). 2012;31(6):1260-68.

18. Kaplan C, Zhang Y. The January effect: medication reinitiation among Medicare Part D beneficiaries. Health Econ. 2014;23(11):1287-300.

19. U.S. Food and Drug Administration. Sildenafil citrate (marketed as Viagra) information for healthcare professionals (7/2005). July 2005. Available at: http://www.fda.gov/Drugs/DrugSafety/PostmarketDrug SafetyInformationforPatientsandProviders/ucm162862.htm. Accessed May 30, 2016

20. U.S. Food and Drug Administration. Information for healthcare professionals: Sildenafil (marketed as Viagra and Revatio), Vardenafil (marketed as Levitra), Tadalafil (marketed as Cialis). November 2007. Available at: http://www.fda.gov/Drugs/DrugSafety/PostmarketDrugSafetyInformationfor PatientsandProviders/ucm124841.htm. Accessed May 30, 2016.

21. Harrold LR, Gurwitz JH, Field TS, et al. The diffusion of a novel therapy into clinical practice: the case of sildenafil. Arch Intern Med. 2000;160(22):3401-05.

22. Cooke CE, Wong W, Lee H. Utilization and cost of sildenafil in a large managed care organization with a quantity limit on sildenafil. J Manag Care Pharm. 2005;11(8):674-80. Available at: http://www.amcp.org/data/jmcp/ Original\%20Research\%20674-680.pdf.

23. Kozman D, Graziul C, Gibbons R, Alexander GC. Association between unemployment rates and prescription drug utilization in the United States, 2007-2010. BMC Health Serv Res. 2012;12:435.

24. Stroupe KT, Smith BM, Hogan TP, et al. Medication acquisition across systems of care and patient-provider communication among older veterans. Am J Health Syst Pharm. 2013;70(9):804-13. 